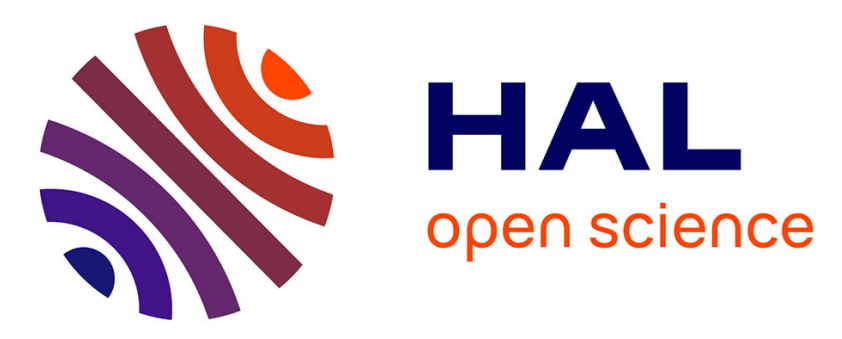

\title{
4-hydroxynonenal in foodstuffs: heme concentration, fatty acid composition and freeze-drying are determining factors
}

Nicole Gasc, Sylviane Taché, Estelle Rathahao, Justine Bertrand-Michel, Véronique Roques, Françoise Guéraud

\section{To cite this version:}

Nicole Gasc, Sylviane Taché, Estelle Rathahao, Justine Bertrand-Michel, Véronique Roques, et al.. 4-hydroxynonenal in foodstuffs: heme concentration, fatty acid composition and freeze-drying are determining factors. Redox Report, 2007, 12 (1), pp.40-4. 10.1179/135100007X162257 . hal-02655296

\section{HAL Id: hal-02655296 \\ https: / hal.inrae.fr/hal-02655296}

Submitted on 29 May 2020

HAL is a multi-disciplinary open access archive for the deposit and dissemination of scientific research documents, whether they are published or not. The documents may come from teaching and research institutions in France or abroad, or from public or private research centers.
L'archive ouverte pluridisciplinaire HAL, est destinée au dépôt et à la diffusion de documents scientifiques de niveau recherche, publiés ou non, émanant des établissements d'enseignement et de recherche français ou étrangers, des laboratoires publics ou privés. 


\title{
4-Hydroxynonenal in foodstuffs: heme concentration, fatty acid composition and freeze-drying are determining factors
}

\author{
Nicole Gasc ${ }^{1}$, Sylviane Taché ${ }^{1}$, Estelle Rathahao ${ }^{1}$, Justine Bertrand-Michel², \\ Véronique Roques ${ }^{2}$, Françoise Guéraud ${ }^{1}$ \\ ${ }^{1}$ Laboratoire des Xénobiotiques, UMR 1089 INRA-ENVT, Toulouse, France \\ ${ }^{2}$ Plateau technique de lipidomique, IFR 30 - Génopôle Toulouse, INSERM U563,CHU Purpan, Toulouse, France
}

\begin{abstract}
4-Hydroxynonenal (HNE) is a product of lipid peroxidation. It has been often used as a biomarker of endogenous lipid peroxidation and its concentration is increased in several diseases. But HNE is not only formed during lipid peroxidation occurring in the body. Some authors have shown that it is also present in oxidized oils and in meats. The aim of this study is to compare the effect of food composition (heme iron, fatty acid composition) or freeze-drying on HNE formation in foodstuffs. The methodology is based on extraction/purification procedure followed by HPLC separation with UV detection. As HNE is chemically very reactive and binds easily to proteins, we used radiolabeled HNE to calculate extraction efficiency, so total HNE can be estimated as only free HNE can be measured. The concomitant presence of both heme iron and omega 6 fatty acids, such as linoleic acid, is important for HNE formation in foodstuffs. Freeze-drying increases this formation.
\end{abstract}

Keywords: 4-Hydroxynonenal, foodstuffs, heme, fatty acids, freeze-drying

\section{INTRODUCTION}

Oxidative stress and resulting lipid peroxidation are supposed to be involved in the pathogenesis of numerous diseases including inflammatory, cardiovascular and neurodegenerative diseases and cancer. 4-Hydroxynonenal (HNE), a major secondary oxidation product of lipid peroxidation of omega 6 fatty acids present in biological membranes in cells and tissues, is believed to be a 'second messenger of oxidative stress' because it may also be involved in the pathogenesis of these diseases. For a long time, this compound has been considered only as a mere lipid peroxidation derived compound, with genotoxic and cytotoxic properties. More recently, it has also been shown to play a real biological role, acting as a signaling molecule under normal and pathological conditions, particularly in cell cycle regulation. ${ }^{1,2}$ The literature concerning HNE has been focused mainly on its endogenous formation and its consequences. However,

Correspondence to: Françoise Guéraud, Institut National de la Recherche Agronomique, UMR 1089 laboratoire des Xenobiotiques, $180 \mathrm{ch}$. de Tournefeuille, BP3, 31931, Toulouse Cedex 9, France

E-mail: fgueraud@toulouse.inra.fr several authors have shown that it is present in various foodstuffs, including oils and meats and some authors have proposed that this compound would be useful as a marker of food quality as far as rancidity is concerned. ${ }^{3,4}$ In the present study, we measured HNE in various meats and in cooked cured pork products but also in rat diets formulated to contain different amounts of heme iron. We developed a methodology using radiolabeled HNE to quantify extraction recovery. The effect of fatty acid composition, heme content and of freeze-drying are discussed, together with the consequences of HNE in foodstuffs on human health.

\section{MATERIALS AND METHODS}

\section{Chemicals}

4-HNE was purchased in its protected form (4-HNEdimethylacetal) from Alexis Corp. and hydrolyzed with $\mathrm{HCl} 1 \mathrm{mM}$ just before use. $\left[4-{ }^{3} \mathrm{H}\right]-\mathrm{HNE}$ diethylacetal was synthesized at CEA, Service des Molécules Marquées CEN (Saclay, France) according to a method developed in the laboratory. ${ }^{5}$ All solvents were HPLC 

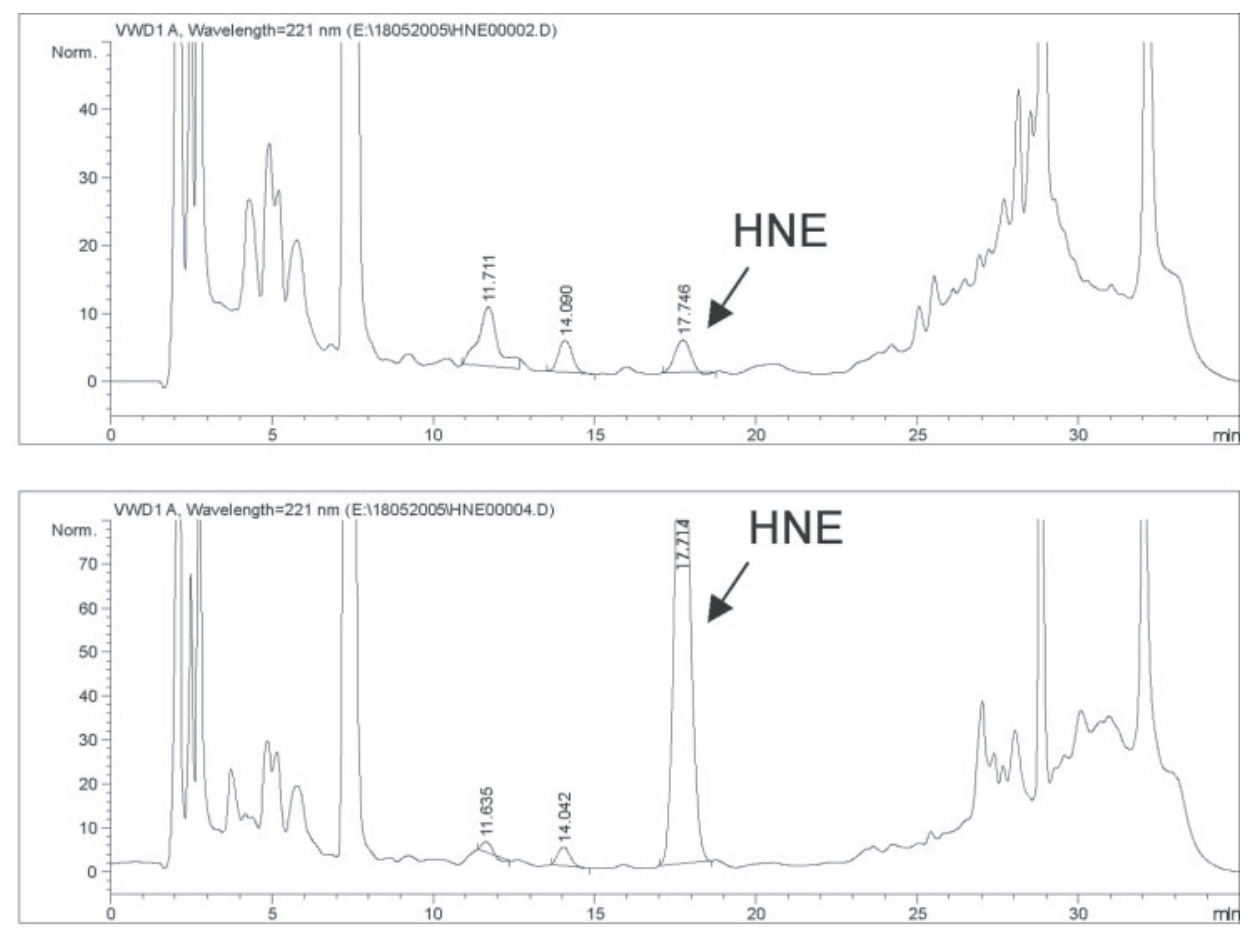

A

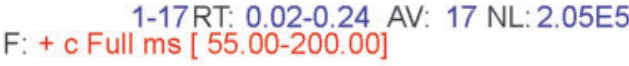

F: + c Full ms [55.00-200.00]

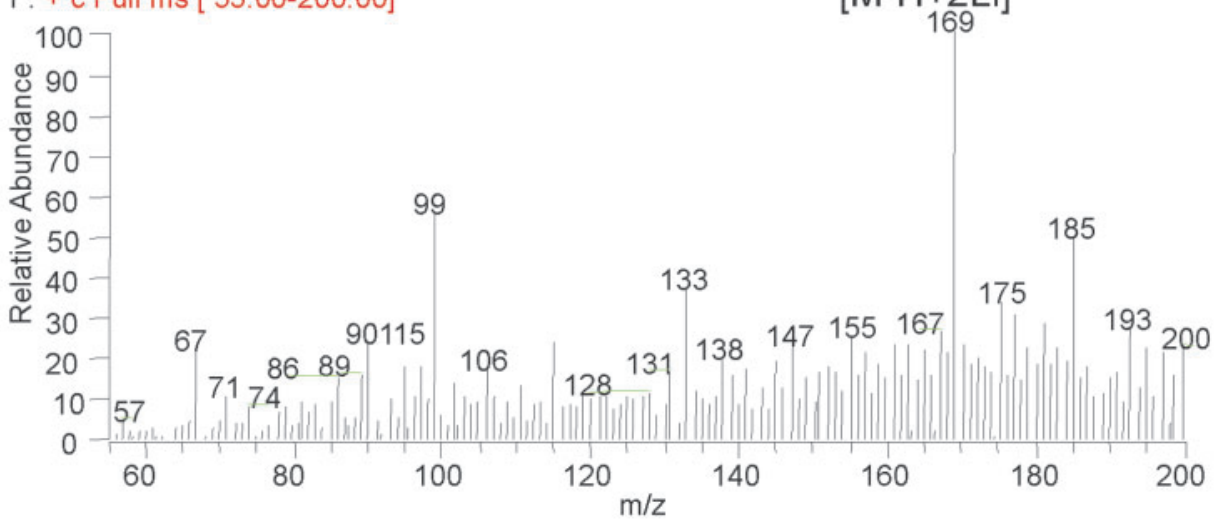

37-51 RT: 0.58-1.07 AV: $15 \mathrm{NL}: 5.34 \mathrm{E} 4$

F: + c Full ms2169.20@36.00 [ 55.00-180.00]

$[\mathrm{M}-\mathrm{H}+2 \mathrm{Li}]^{+}$

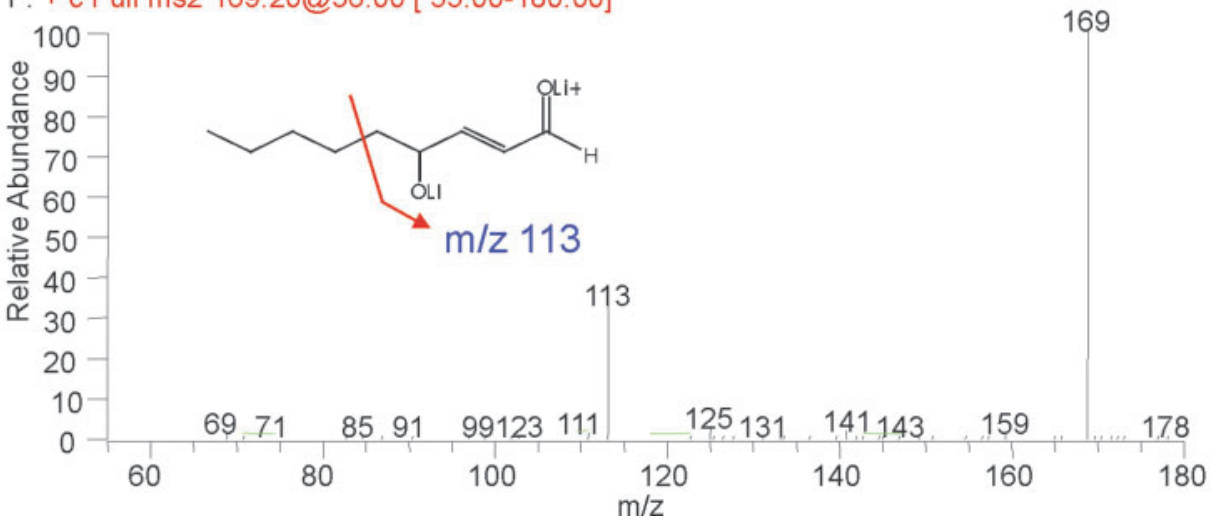

Fig. 1. (A) HPLC analysis of blood sausage extract. Top: blood sausage sample analyzed for HNE; Bottom: idem + HNE standard. (B) Mass spectra of HNE extracted from blood sausage. 


\section{Gasc, Taché, Rathahao, Bertrand-Michel, Roques, Guéraud}

grade. Ethyl acetate, chloroform, methanol and glyceryl triheptadecanoate were obtained from Sigma.

\section{Samples}

Meat samples (chicken breast without skin and beef ribs) and cooked or cooked cured pork products (pork blood sausage with meat pieces, liver pâté, ham and salami) were purchased in a local supermarket. They were cut into small pieces and the fatty parts were removed.

Rat diet samples were homogenized in water directly. These rat diets were based on a modified AIN-76 diet in a powdered form. They were formulated to contain varying concentrations of heme as hemoglobin or myoglobin by the addition of freeze-dried beef, chicken or black pudding at $60 \%$ meat of the total diet, while the control diet contained only casein as protein source. ${ }^{6}$ They all contained 5\% safflower oil. For the study of freeze-drying, an aliquot of each sample was freeze-dried in a lyophilizer and stored at $-20^{\circ} \mathrm{C}$ until analysis.

\section{Heme assay}

The amount of heme in meat was determined according to Van den Berg et al. ${ }^{7}$ Salami and ham were analyzed for heme as hematin by the method of Hornsey. ${ }^{8}$

\section{Measurement of total fatty acid methyl ester molecular species (FAME) by gas-liquid chromatography}

Samples were weighed and then crushed using an UltraTurrax in $2 \mathrm{ml}$ of methanol/5 mM EGTA $(2: 1, \mathrm{v} / \mathrm{v})$. Aliquots corresponding to an equivalent of $0.5 \mathrm{mg}$ of tissues were evaporated, the dry pellets were dissolved in $0.5 \mathrm{ml}$ of $\mathrm{NaOH}(0.1 \mathrm{M})$ overnight and proteins were measured with the Bio-Rad assay. Lipids corresponding to an equivalent of $1 \mathrm{mg}$ of tissue were extracted in chloroform/methanol/water $(2.5: 2.5: 2.1, \mathrm{v} / \mathrm{v} / \mathrm{v})$, in the presence of the internal standard glyceryl triheptadecanoate (1 $\mu \mathrm{g})$. The chloroform phase was filtered over glass wool and evaporated to dryness. The lipid extract was transmethylated with $1 \mathrm{ml}$ of acetyl chloride in methanol $(1: 20, \mathrm{v} / \mathrm{v})$ for $90 \mathrm{~min}$ at $55^{\circ} \mathrm{C}$. After evaporation to dryness, the FAMEs were extracted with $2 \mathrm{ml}$ of hexane in the presence of $2 \mathrm{ml}$ of water. The organic phase was evaporated to dryness, and dissolved in $50 \mu$ of ethyl acetate. Aliquots of FAME $(1 \mu \mathrm{l})$ were analysed by gasliquid chromatography ${ }^{9}$ on a 5890 Hewlett Packard system using a Famewax RESTEK fused silica capillary column (30 m x $0.32 \mathrm{~mm}$ i.d, $0.25 \mathrm{~mm}$ film thickness) and equipped with a flame ionisation detector. Oven temperature was programmed from $110^{\circ} \mathrm{C}$ to $220^{\circ} \mathrm{C}$ at a rate of $2^{\circ} \mathrm{C}$ per min and the carrier gas was hydrogen ( 0.5 bar). The injector and the detector were set at $225^{\circ} \mathrm{C}$ and $245^{\circ} \mathrm{C}$, respectively.

\section{4-HNE analysis}

Food or rat diet samples (1-2 g) were homogenized in $30 \mathrm{ml}$ water with an Ultra-Turrax for $2 \mathrm{~min}$ and then centrifuged (10,000 rpm/10 min). The residue was homogenized and centrifuged again. The supernatants were pooled and lipophilic compounds were extracted twice with $60 \mathrm{ml}$ of dichloromethane. Organic phases were evaporated under reduced pressure. The extract was delipidated using a partition between $16 \mathrm{ml}$ isooctane saturated acetonitrile and $4 \mathrm{ml}$ acetonitrile saturated isooctane. Acetonitrile was evaporated under reduced pressure and the dry extract containing HNE was dissolved in $500 \mu \mathrm{l}$ acetonitrile/water $(50 / 50, \mathrm{v} / \mathrm{v})$ to be further analyzed by HPLC.

The HPLC system was an Hewlett-Packard pump HP1100 equipped with a reverse phase ODS2 Spherisorb column $(5 \mu \mathrm{m}, 10 \times 4.6 \mathrm{~mm})$. The flow rate was $1 \mathrm{ml} / \mathrm{min}$. 4-HNE detection was achieved with an UV detector set at $221 \mathrm{~nm}$ (Fig. 1A) and radiolabeled HNE was detected using an online radioactivity detector Flo-One A500. A standard curve was used to quantify HNE. In order to calculate the recovery of HNE in the samples, tritiated HNE was added before the extraction and radioactivity was analyzed by radio-HPLC. The presence of HNE was confirmed by mass-spectrometry analysis (Fig. 1B).

\section{RESULTS AND DISCUSSION}

Several methods have been previously developed to measure HNE, with or without a derivatization step. ${ }^{3,4,10}$ In the present study, we chose to measure HNE directly but we used radiolabeled HNE, added before the homogenization step, in order to evaluate HNE that would be bound to the food matrix. Actually, HNE is a very reactive chemical compound, that can make covalent links to various nucleophilic compounds, such as DNA bases or some amino-acids. The effect of the food matrix can change depending on the food itself, as recovery with blood sausage reaches $60 \%$ while recovery with chicken meat drops to $12 \%$ (results not shown). As the covalent link between HNE and the macromolecules may be reversible, it seems important to be able to measure 'bound' HNE and not only 'free' HNE.

\section{HNE and heme concentration}

Rat diets were formulated to maximize, with the use of safflower oil which is rich in the polyunsaturated fatty 
Table 1. Iron, heme and 4-hydroxynonenal contents in rat diets and meat samples

\begin{tabular}{lccc}
\hline & $\begin{array}{c}\text { Iron } \\
(\mathrm{mg} / \mathrm{kg})\end{array}$ & $\begin{array}{c}\text { Heme } \\
(\mathrm{mg} / \mathrm{kg})\end{array}$ & $\begin{array}{c}\mathrm{HNE} \\
(\mathrm{mg} / \mathrm{kg})\end{array}$ \\
\hline Rat diets & & & \\
$\quad$ Control diet & 140 & $\mathrm{ND}$ & 0.14 \\
Chicken diet & 140 & $\mathrm{ND}$ & 0.79 \\
Beef meat diet & 140 & 220 & 3.31 \\
$\quad$ Black pudding diet & 950 & 5900 & 66.40 \\
Meat samples & & & \\
Chicken meat & 10 & $\mathrm{ND}$ & $\mathrm{ND}$ \\
Beef meat & 20 & 180 & $\mathrm{ND}$ \\
Liver pâté & 240 & 210 & 0.11 \\
Blood sausage (I)* & 130 & 1040 & 12.51 \\
\hline
\end{tabular}

ND, not detectable; HNE, 4-hydroxynonenal.

*Blood sausage (I) Table 1 and (II) Table 2 came from different suppliers.

acid (PUFA) linoleic acid and poor in natural antioxidants, the peroxidative processes linked to the presence of oxidant compounds (iron or heme iron) in order to study the colon cancer promoting properties of these diets, ${ }^{6}$ as lipid peroxidation may be involved in colon carcinogenesis. All those diets, were balanced for iron with iron citrate except the black pudding diet in which black pudding is very rich in iron as heme.

Heme iron, rather than 'free' iron is associated with HNE formation in rat diets and in foodstuffs (Table 1). Hemoglobin and myoglobin are rich in histidine. HNE easily forms adducts with histidine, which can affect the redox stability of the heme proteins by increasing their oxidation status, thereby increasing lipid oxidation and producing more HNE. ${ }^{11,12}$ As rat diets are rich in linoleic acid, which gives HNE when oxidized, the phenomenon is very important with black pudding diet which amounts 66 ppm of HNE.

It is important to note that heme and especially HNE content may vary dramatically between samples of meat and particularly cooked and processed meat. In the present study, blood sausage HNE content varied more than 15 times between the two different samples coming from different suppliers (Tables 1 and 2, blood sausages I and II). This can be explained by a different composition, including $\mathrm{NaCl}^{13}$ and antioxidant content, or different storage conditions (duration, temperature, etc.). ${ }^{14}$ Some authors have already reported such variability in HNE concentration in smoked ham. ${ }^{15}$

\section{HNE, freeze-drying and fatty acid composition}

Freeze-drying increases HNE formation, especially in foodstuffs containing nitrosylated heme which is present in cured products (Table 2). This can be explained by the low water activity $\left(a_{\mathrm{w}}\right)$ found after freeze-drying. Some authors reported that freeze-dried beef was more stable to oxidation at an $a_{\mathrm{w}}$ of 0.27 than at a lower $a_{\mathrm{w}}{ }^{16}$

Results from Table 2 show that both heme and omega 6 fatty acid concentrations are important for HNE formation. Omega 6 PUFAs are associated with HNE formation because HNE comes from omega 6 fatty acid oxidation. Chicken meat that contains no detectable heme and middle concentrations of both linoleic and arachidonic acids has no detectable HNE formation. Beef meat that contains low omega 6 fatty acids and middle heme concentration has no detectable HNE formation either, even when freeze-dried. On the contrary, ham and salami that have a high concentration of linoleic acid and a middle concentration of heme show very significant HNE formation (more than $6 \mathrm{ppm}$ ), but only after freeze-drying. Blood sausage that has a high concentration of both heme and linoleic acid, shows a significant formation of HNE (2.4 ppm), even without freeze-drying $(0.82 \mathrm{ppm})$. So the mechanisms involved in HNE formation in foodstuffs surely involve heme iron as pro-oxidant, and omega 6 fatty acids as precursors; probably other compounds such as antioxidants could decrease this formation.

\section{Consequences}

Consumption of red meat and blood sausage is associated with increased colorectal cancer risk as shown by

Table 2. Heme, omega 6 fatty acid and 4-hydroxynonenal contents in fresh and freeze-dried meat samples

\begin{tabular}{|c|c|c|c|c|c|}
\hline \multirow[t]{2}{*}{ Meat } & \multirow{2}{*}{$\begin{array}{c}\text { Heme } \\
(\mathrm{mg} / \mathrm{kg})\end{array}$} & \multicolumn{2}{|c|}{ Omega 6 fatty acids $(\mathrm{nmol} / \mathrm{mg})$} & \multicolumn{2}{|c|}{$\mathrm{HNE}(\mathrm{mg} / \mathrm{kg})$} \\
\hline & & Linoleic acid & Arachidonic acid & Freeze-dried & No treatment \\
\hline Chicken meat & ND & 36.2 & 22.2 & ND & ND \\
\hline Beef meat & 180 & 20.6 & 7.1 & ND & ND \\
\hline Ham & 80 & 107.6 & 3.7 & 6.19 & ND \\
\hline Salami & 88 & 221.0 & 8.5 & 6.73 & ND \\
\hline Blood sausage (II)* & 540 & 270.2 & 7.6 & 2.44 & 0.82 \\
\hline
\end{tabular}

ND, not detectable; HNE, 4-hydroxynonenal.

*Blood sausage (I) Table 1 and (II) Table 2 came from different suppliers. 


\section{Gasc, Taché, Rathahao, Bertrand-Michel, Roques, Guéraud}

epidemiological studies. ${ }^{17,18}$ Animal studies show that heme promotes preneoplastic lesions in cancer initiated rats. ${ }^{6}$ Omega 6 fatty acids also promote preneoplastic lesions in such rats, while omega 3 fatty acids have a rather protective effect. ${ }^{19}$ As $\mathrm{HNE}$ is one of the major oxidation product of omega 6 fatty acids and comes only from omega 6 fatty acid oxidation, one can hypothesize that HNE may play a role in colon cancer development. Very recently, we have shown that fecal waters from rats fed heme and an omega 6 rich diet could be more cytotoxic, when added to the culture medium, to mouse colon wild-type cells as compared to premalignant cells that had already been mutated for Apc gene, thereby conferring a selective advantage to those mutated cells. ${ }^{20}$ Apc mutation is an early event in human colon cancer development. HNE has been found in those fecal waters. Moreover, when added under the same conditions to the culture medium, HNE mimics the effects of those fecal waters. ${ }^{20} \mathrm{HNE}$ may then contribute to the effect of heme iron and omega 6 fatty acids on colon cancer development. The effect other lipid peroxidation products, such as 4-hydroxyhexenal, that comes specifically from omega 3 fatty acid oxidation, is now under investigation.

\section{ACKNOWLEDGEMENT}

The project was partly supported by Lipidomics of the Functional Exploration Platform of Toulouse Genopole ${ }^{\circledR}$.

\section{REFERENCES}

1. Zarkovic N, Zarkovic K, Schaur RJ et al. 4-Hydroxynonenal as a second messenger of free radicals and growth modifying factor. Life Sci 1999; 65: 1901-1904.

2. Dianzani MU. 4-Hydroxynonenal and cell signalling. Free Radic Res 1998; 28: 553-560.

3. Sakai T, Kuwazuru S, Yamauchi K, Uchida K. A lipid peroxidationderived aldehyde, 4-hydroxy-2-nonenal and omega 6 fatty acids contents in meats. Biosci Biotechnol Biochem 1995; 59: 1379-1380.

4. Uchida T, Gotoh N, Wada S. Method for analysis of 4-hydroxy2-(E)-nonenal with solid-phase microextraction. Lipids 2002; 37: 621-626.

5. Bravais F, Rao D, Alary J, Rao RC, Debrauwer L, Bories G. Synthesis of 4-hydroxy[4-H-3]-2(E)-nonen-1-al-diethylacetal. $J$
Label Compounds Radiopharmaceut 1995; 36: 471-477.

6. Pierre F, Freeman A, Tache S, Van der Meer R, Corpet DE. Beef meat and blood sausage promote the formation of azoxymethaneinduced mucin-depleted foci and aberrant crypt foci in rat colons. J Nutr 2004; 134: 2711-2716.

7. van den Berg JW, Koole-Lesuis R, Edixhoven-Bosdijk A, Brouwers N. Automating the quantification of heme in feces. Clin Chem 1988; 34: 2125-2126.

8. Hornsey HC. The colour of cooked cured pork. I - Estimation of the nitric oxide-haem pigments. J Sci Food Agric 1956; 7.

9. Lillington JM, Trafford DJ, Makin HL. A rapid and simple method for the esterification of fatty acids and steroid carboxylic acids prior to gas-liquid chromatography. Clin Chim Acta 1981; 111: 91-98.

10. Zanardi E, Jagersma CG, Ghidini S, Chizzolini R. Solid phase extraction and liquid chromatography-tandem mass spectrometry for the evaluation of 4-hydroxy-2-nonenal in pork products. $J$ Agric Food Chem 2002; 50: 5268-5272.

11. Faustman C, Liebler DC, McClure TD, Sun Q. Alpha, betaunsaturated aldehydes accelerate oxymyoglobin oxidation. $J$ Agric Food Chem 1999; 47: 3140-3144.

12. Suman SP, Faustman C, Stamer SL, Liebler DC. Redox instability induced by 4-hydroxy-2-nonenal in porcine and bovine myoglobins at pH 5.6 and 4 degrees C. J Agric Food Chem 2006; 54: 3402-3408.

13. Sakai T, Shimizu Y, Kawahara S. Effect of $\mathrm{NaCl}$ on the lipid peroxidation-derived aldehyde, 4-hydroxy-2-nonenal, formation in boiled pork. Biosci Biotechnol Biochem 2006; 70: 815-820.

14. Sakai T, Yamauchi K, Kuwazuru S, Gotoh N. Relationships between 4-hydroxy-2-nonenal, 2-thiobarbituric acid reactive substances and n-6 polyunsaturated fatty acids in refrigerated and frozen pork. Biosci Biotechnol Biochem 1998; 62: 2028-2029.

15. Munasinghe DMS, Ichimaru K, Matsui T, Sugamoto K, Sakai T. Lipid peroxidation-derived cytotoxic aldehyde, 4-hydroxy-2nonenal in smoked pork. Meat Sci 2003; 63: 377-380.

16. Quaglia GG, Sinesio F, Veccia-Scavalli D, Avalle V, Scalfati G. Effect of water activity on oxidative deterioration of freeze-dried beef. Int J Food Sci Technol 1988; 23: 241-246.

17. Norat T, Riboli E. Meat consumption and colorectal cancer: a review of epidemiologic evidence. Nutr Rev 2001; 59: 37-47.

18. Larsson SC, Rafter J, Holmberg L, Bergkvist L, Wolk A. Red meat consumption and risk of cancers of the proximal colon, distal colon and rectum: the Swedish Mammography Cohort. Int J Cancer 2005; 113: 829-834.

19. Dommels YE, Heemskerk S, van den Berg H, Alink GM, van Bladeren PJ, van Ommen B. Effects of high fat fish oil and high fat corn oil diets on initiation of AOM-induced colonic aberrant crypt foci in male F344 rats. Food Chem Toxicol 2003; 41: 1739-1747.

20. Pierre F, Taché S, Guéraud F, Rérole AL, Jourdan M-L, Petit C. Apc mutation induces resistance of colonic cells to lipoperoxidetriggered apoptosis induced by faecal water from haem-fed rats. Carcinogenesis 2006; In press (online). 